\title{
Written instructions versus physiotherapist- supervised rehabilitation after acute ankle sprain
}

Kristin Gustafsson, Anne Fältström, Ulrika Öberg and Ann-Sofi Kammerlind

The self-archived postprint version of this journal article is available at Linköping University Institutional Repository (DiVA):

http:// urn.kb.se/ resolve?urn=urn:nbn:se:liu:diva-136104

N.B.: When citing this work, cite the original publication.

This is an electronic version of an article published in:

Gustafsson, K., Fältström, A., Öberg, U., Kammerlind, A., (2017), Written instructions versus physiotherapist-supervised rehabilitation after acute ankle sprain, European J ournal of Physiotherapy, 19(2), 76-83. https:/ / doi.org/ 10.1080/ 21679169.2016.1251966

Original publication available at:

https:// doi.org/ 10.1080/21679169.2016.1251966

Copyright: Taylor \& Francis (STM, Behavioural Science and Public Health Titles)

http:// www.tandf.co.uk/journals/ default.asp 


\section{Title}

Written instructions versus physiotherapist-supervised rehabilitation after acute ankle sprain

\section{Authors}

Kristin Gustafsson ${ }^{1}$, Anne Fältström ${ }^{1,2}$, Ulrika Öberg ${ }^{3,4}$, Ann-Sofi Kammerlind ${ }^{2,5}$

${ }^{1}$ Department of Physiotherapy, Rehabilitation Centre, Ryhov County Hospital, Jönköping, Sweden

${ }^{2}$ Division of Physiotherapy, Department of Medical and Health Sciences, Linköping University, Linköping, Sweden

${ }^{3}$ Formerly with Futurum - Academy for Health and Care, Region Jönköping County, Jönköping, Sweden

${ }^{4}$ Formerly with Division of Physiotherapy, Department of Medical and Health Sciences, Linköping University, Linköping, Sweden

${ }^{5}$ Futurum - Academy for Health and Care, Region Jönköping County, Jönköping, Sweden

\section{Corresponding author}

Kristin Gustafsson. Department of Physiotherapy, Rehabilitation Centre, Ryhov County Hospital, 55185 Jönköping, Sweden. Phone: +46 (0)36-32 18 50. E-mail:

kristin.gustafsson@rjl.se.

\section{Declaration of interest}

The study was financially supported,compensation for working time and costs associated with the project, by Futurum - Academy for Health and Care, Region Jönköping County. 


\section{Title}

\section{Written instructions versus physiotherapist-supervised rehabilitation after acute ankle}

sprain

\section{Abstract}

The aim of this study was to compare the effects of written instructions versus physiotherapist-supervised rehabilitation on patient-rated ankle function, satisfaction, and physical activity ability after an acute ankle sprain. Thirty-nine patients with an acute ankle sprain, recruited from an emergency department, received written instructions on functional rehabilitation (WI group). The patients were evaluated 6 weeks and 3 months after their injury with the disease-specific Foot and Ankle Outcome Score (FAOS). The patients also rated how satisfied they were with their ankle and physical activity ability using visual analogue scales. The results from the WI group were compared with a group of patients $(n=33)$ who received physiotherapist-supervised rehabilitation in a previous study (PT group). We found that compared with the PT group, the WI group had significantly worse scores in all of the FAOS subscales 6 weeks after the injury, and in three of five subscales 3 months after the injury. They also rated signigicantly lower satisfaction and significantly lower physical activity ability at both follow-ups. In conclusion, physiotherapist-supervised rehabilitation was more effective than written instructions on improving patient-rated ankle function, satisfaction, and physical activity ability after an acute ankle sprain.

Key words: Patient education hand out, home-based physiotherapy treatment, self-care, FAOS 


\section{Introduction}

Ankle sprains are the most commonly treated sports and recreational injury $(1,2)$, and account for a significant number of consultations in emergency departments (EDs) (3). The incidence has been estimated to be one ankle sprain per 10000 people per day (4). The injury generates a cost to society that is larger than many earlier have realised (2). Approximately $30 \%$ of patients with ankle sprains report chronic ankle problems such as pain, instability, and stiffness several years after their injury $(5,6)$. These persistent disabilities can lead to chronic ankle instability (CAI) and an increased risk of posttraumatic osteoartrhritis (PTOA) in the injured ankle (2). In 16\% of the PTOA cases the cause is a ligamentous lesion (7). The high rate of residual symptoms suggests that ankle sprains are not always managed correctly (8), since the risk of residual symptoms increases if the ankle treatment and rehabilitation are inadequate (9). There is a need for clearly defined acute care, increased knowledge about rehabilitation methods and continued research to determine the optimal treatment of an acute ankle sprain $(10,11)$; as a result, there is still no uniform management of this injury $(9,12)$.

Several studies $(9,13-15)$ have shown that early functional treatment $(14,15)$ is most effective and emphasize the importance of supervised rehabilitation after an acute ankle sprain. However, early functional treatment is rarely used in daily clinical practice since ankle sprains are assumed to recover naturally with little or no rehabilitation (16). In EDs, it can be hard to prioritize the patients' needs regarding accurate information and instructions (15) and patients with an acute ankle sprain are not routinely referred to physiotherapy departments for further rehabilitation $(16,17)$. Chorley demonstrated that less than $1 \%$ of patients discharged from an ED with acute ankle sprain received information on the essential components for management and rehabilitation (18). Patients who participate in organized athletics more often receive supervised rehabilitation compared with a general population (14). 
Previously, the authors of this article (15) showed physiotherapist-supervised rehabilitation had a more positive effect on patient-rated ankle function, satisfaction, and physical activity ability than receiving no specific rehabilitation in the first 6 weeks after an acute ankle sprain. After that study the question arose if the worse result in the group receiving no specific rehabilitation was due to a lack of information or lack of supervision. There is evidence supporting that patient information interventions (e.g. pamphlets) are effective for several orthopaedic conditions (19), but their utility in rehabilitation after an acute ankle sprain is still unclear. In a systematic review comparing supervised rehabilitation with home exercise programs reported some benefits for the patients receiving supervised rehabilitation (14). However the included studies focused mostly on objective measures and resprains or included scheduled appointments also for the patients receiving home exercise programs. The effect of written instructions alone on patient-reported outcome measures is still to be considered unclear. Therefore, the aim of this study was to compare the effects of written instructions versus physiotherapist-supervised rehabilitation on patient-rated ankle function, satisfaction, and physical activity ability after an acute ankle sprain.

\section{Material and Methods}

\section{Study design and participants}

Fifty-three consecutive patients (representing a general population) from an ED at a general hospital in Sweden were assessed for eligibility to be included in the written instruction (WI) group. The inclusion criteria were (a) acute ankle sprain grade I-III, where x-ray or obvious clinical signs showed no fracture (20), (b) aged 18-65 years old, and (c) proficient in the Swedish language. Exclusion criteria were (a) earlier fracture or surgery of the injured ankle, (b) injuries or disease in the lower extremities causing major activity-limiting disorders, (c) 
ankle sprain in the same ankle requiring health care during the previous year, and (d) treatment of the injured ankle by another physiotherapist at the inclusion.

The patients were contacted by phone as soon as possible after the visit to the ED (median 1 day, range 0-6 days) and offered participation. After accepting all patients received oral and written information about the study, and signed their informed consent. The Regional Ethical Review Board in Linköping, Sweden approved the study.

The results of the WI group were compared with a group of 33 patients recruited from the same ED who received physiotherapist-supervised rehabilitation in a previous study (PT group) (15). The inclusion and exclusion criteria for the PT group were the same as for the WI group except for another exclusion criteria (d); no treatment by another physiotherapist outside the study during the whole evaluation time.

There is no standardized treatment regime for this patient group at the ED, all patients seeking care at the ED after an acute ankle sprain receive conventional treatment regardless participation in this study or not. Conventional treatment after an acute ankle sprain includes an examination of the ankle, usually a short period of weight unloading with crutches, elastic wrap, and verbal and/or written information from the attending physician or nurse, but since the staff at the ED changes frequently, the conventional treatment can differ from patient to patient depending on whom they meet.

\section{Intervention}

Patients in the WI group received written instructions about functional treatment and information about when it is appropriate to return to prior levels of activity, training, and competition after the injury (Appendix). The patients in the WI group also had the opportunity to call the physiotherapist in charge of the study (AF) with questions during the follow-up 
period. No information was collected regarding what other treatments or self-management, other than physiotherapy, the patients in the WI group used during the follow-up period.

Patients in the PT group received instructions about functional treatment and exercises during four visits to a physiotherapist (AF). The first visit took place as soon as possible after the injury (median 4 days, range 1-14 days), and follow-ups after 3 weeks, 6 weeks and 3 months. The visits included an examination of the injured ankle, information of the ankle anatomy and function, and instructions about home exercises. The exercises were functionally based, allowing the patient to progress according to his or her functional ability. They also received the same information about when it was appropriate to return to prior levels of activity, training, and competition orally as the WI group did in writing. Two patients in the PT group used a brace during some weeks of the follow-up period. The intervention for the PT group was previously described in detail (15).

The intent was to measure how well the patients complied to the given exercises by a training diary in the PT group, but most of the diaries were incomplete and the information in the few completed diaries were difficult to compile (15). Therefore it was decided not to mearsure compliance in the WI group.

\section{Outcome Measures}

Both groups were evaluated with the same self-administrated questionnaires 6 weeks and 3 months after the injury. The questionnaires contained questions about patient characteristics and the primary outcome measures, as described below. Working conditions were selfreported on a scale from 0-6 (modified from Steven Edworthy, McCraig Centre for Joint Injury \& Arthritis Research, Calgary, Alberta, Canada) (Table 1).

The PT group completed the questionnaire at their visit to the physiotherapist. The WI group received the questionnaires by mail and non-responders received up to two reminders. 
Foot and Ankle Outcome Score (FAOS)

The FAOS was the primary outcome measure to evaluate ankle function. The FAOS is a 42item, self-administrated questionnaire (21) that assesses symptoms and functional limits across five domains: Pain, Symptoms, Activities of daily life (ADL), Sports and recreation function (Sport/Rec), and Foot- and ankle-related quality of life (QOL). A score from 0 (worse result) to 100 (best result) is calculated for each subscale. The validity and test-retest reliability for the FAOS has been tested with good results indicating it is a useful measure for detecting small changes over time in subjects with lateral ankle ligament injuries (21). A 10 point score change on the FAOS indicates a clinical change (22).

\section{Visual analogue scale (VAS)}

A VAS was used to assess patient-rated satisfaction and physical activity ability. The patients answered the question “How satisfied are you with your ankle?” by marking a cross on a 100mm line situated between two polar descriptors ("completely satisfied” and "not satisfied at all”). The question “Compared with normal, how would you rate your physical activity ability today?” was answered by marking a cross between “normal, no limitation” and "severely limited” (23). The VAS was previously shown to be a reliable and valid technique for measuring subjective phenomena, such as satisfaction, QOL, and pain (24).

\section{Statistical analysis}

Prior to the study, a power analysis was carried out and determined that a total of 60 patients were needed to detect a clinically significant median score difference of 10 points in the subscale pain of the FAOS when comparing two groups, with $80 \%$ power and at $p=0.05$ (25). Medians, first and third quartile (Q1-Q3), and range were calculated for the descriptive data, since both groups were not normally distributed in all variables. For the comparison between 
the WI group and the PT group, the Chi-square test, Fisher’s exact test, and Mann-Whitney U-test were used, as appropriate. The underlying data obtained from questionnaire FAOS and VAS are ordinal and the Mann-Whitney U-test was used. The statistical analyses were performed using the Statistical Package for Social Sciences (SPSS), version 20.0. The level of significance was set at $p<0.05$.

\section{Results}

Thirty-nine patients were included in the WI group (Fig. 1). The inclusion of the thirty-three patients in the PT group is previously described (15).

The patients in the WI and PT groups were comparable in all characteristics except one (Table 1). In median all patients visited the ED at the same day as the injury occurd (range WI group 0-18 days, range PT group 0-6 days) ( $p=0.883$ ). Two patients in the WI group utilized the possibility to call the physiotherapist in charge (AF) with questions during the study follow-up period. Four patients in the WI group had physiotherapy contact outside the study during the follow-up period (range 1-4 visits).

The WI group reported heavier working conditions before the injury compared with the PT group ( $p=0.022$ ). However, the patients in both groups returned to work after a median of 2 days (range WI group: 0-35 days, range PT group: 0-25 days) ( $p=0.787$ ). This calculation was based on a five-day workweek with weekends off. Three patients in the WI group and nine patients in the PT group were not included in this analysis since they were students or unemployed. 


\section{FAOS}

Physiotherapist-supervised rehabilitation significantly improved the subscales Pain, Symptoms, ADL, Sport/Rec and QOL of FAOS at 6 weeks compared with written instructions alone. After 3 months, there were significant differences in favour of physiotherapist-supervised rehabilitation in the subscales ADL, Sport/Rec, and QOL, but not in Pain and Symptoms (Table 2).

\section{VAS}

Physiotherapist-supervised rehabilitation significantly improved both patient-rated satisfaction and physical activity ability at both follow-ups compared with written instructions alone (Table 2, Fig.2).

\section{Discussion}

The aim of this study was to examine if written instructions about functional treatment, as a complement to verbal information given at the ED, can replace physiotherapist-supervised rehabilitation after an acute ankle sprain. The main findings of the study demonstrated that physiotherapist-supervised rehabilitation is more effective than only written instructions on improving patient-rated ankle function, satisfaction, and physical activity ability after an acute ankle sprain. The PT group showed significantly better results, compared with the WI group, in nearly all parts of the self-administrated scales (FAOS and VAS), at the follow-ups 6 weeks and 3 months after the injury. Three months after the injury, the WI group reached the same level of ankle function, satisfaction and physical activity ability as the PT group had reached at the follow-up 6 weeks after the injury (Table 2, Fig. 2). The better result for the PT group was not only statistically significant, there was also a clinically significant difference between the two groups. For example, the median score for the PT group was 30 points higher 
than the WI group in the subgroup Sport/Rec at 6 weeks after the injury. One possible explanation for the differences between groups is individualized information and training in the PT group. Individuals respond differently to exercises; thus, each training program needs to be adapted to fit the individual's needs (26), which is difficult to accomplish without the human meeting between patient and caregiver. The growing area of e-health can however open new possibilities. Dahlberg et al (27) showed potential to deliver individualized treatment to patients with knee and hip osteoarthritis through a web-based platform. The webbased platform combined video and verbal information with a possibility of communication between therapist and patient by chat. This may be a viable treatment developer even for patients after a ankle sprain.

The authors of this study previously reported on the positive effect of physiotherapistsupervised rehabilitation compared with a control group receiving no specific rehabilitation, in the first 6 weeks after an ankle sprain (15). The present study examined if this previous positive result for the PT group was due to a lack of information provided to the control group or lack of supervision. The new findings reinforce that patients with an ankle sprain need supervision in their rehabilitation and that it is a misperception in today's clinical practice that ankle sprains are simple and self-heal $(15,16)$. Thus, patients should be referred for physiotherapist-supervised rehabilitation.

Earlier studies compared clinical or home-based physiotherapy treatment for patients after acute ankle injuries, such as ankle fractures (28) and posterior tibial tendon dysfunction (29). In contrast to our results, these studies did not find a significant difference in physical function after the treatments, indicating that physiotherapy more often can be home-based. In a recently published systematic review comparing supervised rehabilitation and home exercise programs after acute ankle sprain showed that supervised rehabilitation had some benefits compared with home-based programs regarding pain and subjective ankle instability 
the first 8 weeks (14). Supervised rehabilitation also resulted in greater gain in ankle strength and proprioception at 4 months after an ankle sprain. The few included studies (four) were however only partly comparable with our study, due to study design including scheduled appointments also for the home-based treatment group (30) or due to outcome measures focusing on objective measures (31) or re-sprains and longer follow-ups (32). In addition, the review reported that only $11 \%$ of patients in a general population that had an ankle sprain, received supervised rehabilitation within the first 30 days (14).

It is likely that patients with an acute ankle sprain only need a few visits early on after the injury. The focus needs to be on information and instilling the confidence to start weight bearing and exercises early after the injury, to regain function faster in the ankle and to decrease the risk of recurrent ankle sprains and the development of CAI .This needs to be performed by trained healthcare professionals $(11,15)$. At the same time, programs that train physicians who work in the ED need to include education on the proper treatment, rehabilitation, and follow-up of patients with acute ankle sprains (18). Today in health care, there is a trend for fewer visits to all professions after injuries. However, the results in this study indicate that follow-up by a physiotherapist makes a positive difference after an acute ankle sprain.

Studies investigating alternative treatment options in physiotherapy are important from several perspectives. One perspective is the need to prioritize health care resources and these injuries are more costly for society than earlier known (2). Another perspective is that today's lifestyle tends to have a high tempo and, if possible, patients prefer to perform the rehabilitation where it suits them best. At the same time, home-based treatments require that the patient is responsible for adherence to the treatment (33), as the efficacy of therapeutic exercises can only be established when patients comply with the exercise regime (34). Earlier studies demonstrated that the use of written instructions alone results in poorer exercise 
performance compared with oral instructions given by a therapist and appeared to result in fewer improvements in injuries (35).

There are a number of limitations to the present study. The optimal design of this type of study is a randomized control trial (RCT), to minimize the risk of bias. However, there was no difference between the two groups in this study in patient characteristics. The standard management of ankle sprain injuries at the ED was also the same during both data collections. It would have been beneficial to evaluate the presence of residual symptoms and re-sprains one year after the injury to be able to compare the result with other similar studies (32). A longer follow-up would also have contributed with knowledge about if patients in the two groups developed CAI. The distribution of earlier ankle sprains was similar in the two groups, but we don't know if any of those had CAI before inclusion in the study. Since the recommendation in management of CAI also is functional treatment as for an acute ankle sprain (36), not knowing the prevalence of CAI should not have affected the intervention and the outcome of this study. The prevalence and characteristics of CAI is today well established, but further research are needed about the causes of developing CAI (2) and PTOA (11).

There is no gold standard for how to design written instructions for acute ankle sprains and what information and exercises it should include. The written instructions used in this study (Appendix) were based on the information given to the patients at the visit to the physiotherapist in the initial study (15). The content was similar to other written instructions after acute ankle sprain (37) and these instructions are still used at the ED in the hospital where this study was carried out. We are not aware of the distribution of severity of the injury in the two groups, since the traditional grading system of ankle sprains from grade I (mild) to III (severe) was rarely used by the attending physicians at the ER. This grading is often impossible in an emergency situation, because the pain and swelling prevents full clinical assessment (16). There were no baseline measures in the study which would be of interest to 
gain more knowledge about the progress of the patients. However, since the primary aim was to compare two groups with two different treatment methods and not to follow how each patient improved over time, baseline data was not collected.

RCT-studies with larger numbers of patients, longer evaluation periods and complementary health economic analysis, are needed to better determine the appropriate management after an acute ankle sprain.

\section{Conclusion}

Our findings indicate that physiotherapist-supervised rehabilitation is more effective than written instructions on improving patient-rated ankle function, satisfaction and physical activity ability; therefore, supervised rehabilitation is to prefer over written instructions alone after an acute ankle sprain.

\section{Acknowledgments}

The authors thanks to all patients who participated in the study. Further thanks to Futurum Academy for Health and Care, Region Jönköping County for financially support.

\section{References}

1. Kobayashi T, Gamada K. Lateral Ankle Sprain and Chronic Ankle Instability: A Critical Review. Foot Ankle Spec. 2014 Jun 24;7(4):298-326.

2. Gribble PA, Bleakley CM, Caulfield BM, Docherty CL, Fourchet F, Fong DT, et al. Evidence review for the 2016 International Ankle Consortium consensus statement on the prevalence, impact and long-term consequences of lateral ankle sprains. Br J Sports Med. 2016 Jun 3.

3. Tully MA, Bleakley CM, O'Connor SR, McDonough SM. Functional management of ankle sprains: what volume and intensity of walking is undertaken in the first week postinjury. $\mathrm{Br} \mathrm{J}$ Sports Med. 2012 Sep;46(12):877-82. 
4. Kannus P, Renström P. Treatment for acute tears of the lateral ligaments of the ankle. Operation, cast, or early controlled mobilization. J Bone Joint Surg Am. 1991 Feb;73(2):30512.

5. Anandacoomarasamy A, Barnsley L. Long term outcomes of inversion ankle injuries. $\mathrm{Br} \mathrm{J}$ Sports Med. 2005 Mar;39(3):e14; discussion e.

6. Konradsen L, Bech L, Ehrenbjerg M, Nickelsen T. Seven years follow-up after ankle inversion trauma. Scand J Med Sci Sports. 2002 Jun;12(3):129-35.

7. Valderrabano V, Horisberger M, Russell I, Dougall H, Hintermann B. Etiology of ankle osteoarthritis. Clin Orthop Relat Res. 2009 Jul;467(7):1800-6.

8. Aiken AB, Pelland L, Brison R, Pickett W, Brouwer B. Short-term natural recovery of ankle sprains following discharge from emergency departments. J Orthop Sports Phys Ther. 2008 Sep;38(9):566-71.

9. Kerkhoffs GM, van den Bekerom M, Elders LA, van Beek PA, Hullegie WA, Bloemers GM, et al. Diagnosis, treatment and prevention of ankle sprains: an evidence-based clinical guideline. Br J Sports Med. 2012 Sep;46(12):854-60.

10. Zoch C, Fialka-Moser V, Quittan M. Rehabilitation of ligamentous ankle injuries: a review of recent studies. Br J Sports Med. 2003 Aug;37(4):291-5.

11. Gribble PA, Bleakley CM, Caulfield BM, Docherty CL, Fourchet F, Fong DT, et al. 2016 consensus statement of the International Ankle Consortium: prevalence, impact and long-term consequences of lateral ankle sprains. Br J Sports Med. 2016 Jun 3.

12. Calatayud J, Borreani S, Colado JC, Flandez J, Page P, Andersen LL. Exercise and ankle sprain injuries: a comprehensive review. Phys Sportsmed. 2014 Feb;42(1):88-93.

13. Jones MH, Amendola AS. Acute treatment of inversion ankle sprains: immobilization versus functional treatment. Clin Orthop Relat Res. 2007 Feb;455:169-72.

14. Feger MA, Herb CC, Fraser JJ, Glaviano N, Hertel J. Supervised rehabilitation versus home exercise in the treatment of acute ankle sprains: a systematic review. Clin Sports Med. 2015 Apr;34(2):329-46.

15. Hultman K, Fältström A, Öberg U. The effect of early physiotherapy after an acute ankle sprain. Advances in Physiotherapy. 2010;12(2):65-73.

16. Cooke MW, Lamb SE, Marsh J, Dale J. A survey of current consultant practice of treatment of severe ankle sprains in emergency departments in the United Kingdom. Emerg Med J. 2003 Nov;20(6):505-7. 
17. Feger MA, Glaviano NR, Donovan L, Hart JM, Saliba SA, Park JS, et al. Current Trends in the Management of Lateral Ankle Sprain in the United States. Clin J Sport Med. 2016 Jun 22.

18. Chorley JN. Ankle sprain discharge instructions from the emergency department. Pediatr Emerg Care. 2005 Aug;21(8):498-501.

19. Mayich DJ, Tieszer C, Lawendy A, McCormick W, Sanders D. Role of patient information handouts following operative treatment of ankle fractures: a prospective randomized study. Foot Ankle Int. 2013 Jan;34(1):2-7.

20. Stiell IG, Greenberg GH, McKnight RD, Nair RC, McDowell I, Worthington JR. A study to develop clinical decision rules for the use of radiography in acute ankle injuries. Ann Emerg Med. 1992 Apr;21(4):384-90.

21. Roos EM, Brandsson S, Karlsson J. Validation of the foot and ankle outcome score for ankle ligament reconstruction. Foot Ankle Int. 2001 Oct;22(10):788-94.

22. Roos EM, Lohmander LS. The Knee injury and Osteoarthritis Outcome Score (KOOS): from joint injury to osteoarthritis. Health Qual Life Outcomes. 2003;1:64.

23. Wilson RW, Gansneder BM. Measures of functional limitation as predictors of disablement in athletes with acute ankle sprains. J Orthop Sports Phys Ther. 2000 Sep;30(9):528-35.

24. Miller MD, Ferris DG. Measurement of subjective phenomena in primary care research: the Visual Analogue Scale. Fam Pract Res J. 1993 Mar;13(1):15-24.

25. Roos EM, Engström M, Lagerquist A, Söderberg B. Clinical improvement after 6 weeks of eccentric exercise in patients with mid-portion Achilles tendinopathy -- a randomized trial with 1-year follow-up. Scand J Med Sci Sports. 2004 Oct;14(5):286-95.

26. Malempati C, Jurjans J, Noehren B, Ireland ML, Johnson DL. Current Rehabilitation Concepts for Anterior Cruciate Ligament Surgery in Athletes. Orthopedics. 2015 Nov 1;38(11):689-96.

27. Dahlberg LE, Grahn D, Dahlberg JE, Thorstensson CA. A Web-Based Platform for Patients With Osteoarthritis of the Hip and Knee: A Pilot Study. JMIR Res Protoc. 2016;5(2):e115.

28. Moseley AM, Beckenkamp PR, Haas M, Herbert RD, Lin CW. Rehabilitation After Immobilization for Ankle Fracture: The EXACT Randomized Clinical Trial. Jama. 2015 Oct 6;314(13):1376-85. 
29. Bek N, Simsek IE, Erel S, Yakut Y, Uygur F. Home-based general versus center-based selective rehabilitation in patients with posterior tibial tendon dysfunction. Acta Orthop Traumatol Turc. 2012;46(4):286-92.

30. Bassett SF, Prapavessis H. Home-based physical therapy intervention with adherenceenhancing strategies versus clinic-based management for patients with ankle sprains. Phys Ther. 2007 Sep;87(9):1132-43.

31. Holme E, Magnusson SP, Becher K, Bieler T, Aagaard P, Kjaer M. The effect of supervised rehabilitation on strength, postural sway, position sense and re-injury risk after acute ankle ligament sprain. Scand J Med Sci Sports. 1999 Apr;9(2):104-9.

32. van Rijn RM, van Os AG, Kleinrensink GJ, Bernsen RM, Verhaar JA, Koes BW, et al. Supervised exercises for adults with acute lateral ankle sprain: a randomised controlled trial. Br J Gen Pract. 2007 Oct;57(543):793-800.

33. Simek EM, McPhate L, Haines TP. Adherence to and efficacy of home exercise programs to prevent falls: a systematic review and meta-analysis of the impact of exercise program characteristics. Prev Med. 2012 Oct;55(4):262-75.

34. Sluijs EM, Kok GJ, van der Zee J. Correlates of exercise compliance in physical therapy. Phys Ther. 1993 Nov;73(11):771-82; discussion 83-6.

35. Friedrich M, Cermak T, Maderbacher P. The effect of brochure use versus therapist teaching on patients performing therapeutic exercise and on changes in impairment status. Phys Ther. 1996 Oct;76(10):1082-8.

36. van Ochten JM, van Middelkoop M, Meuffels D, Bierma-Zeinstra SM. Chronic complaints after ankle sprains: a systematic review on effectiveness of treatments. J Orthop Sports Phys Ther. 2014 Nov;44(11):862-71, c1-23.

37. Physicians AAoF. Information from your family doctor. Exercising your ankle after a sprain. Am Fam Physician. 2006 Nov 15;74(10):1725-6.

Appendix. Rehabilitation instructions after an acute ankle sprain. 
Table 1. Patient characteristics.

\begin{tabular}{|c|c|c|c|}
\hline & $\begin{array}{l}\text { Written instruction } \\
\text { group }(n=39)\end{array}$ & $\begin{array}{l}\text { Physiotherapy } \\
\text { group }(n=33)\end{array}$ & $p$-value \\
\hline Gender: male/female $(n)$ & 21/18 & $16 / 17$ & 0.650 \\
\hline Age $(y)^{a}$ & $37(23-46)$ & $33(22.5-45.5)$ & 0.541 \\
\hline Body mass index ${ }^{a}$ & $24.7(23.2-27.5)$ & $24.4(22.5-25.7)$ & 0.277 \\
\hline Injured foot: right/left $(n)$ & 20/19 & $17 / 16$ & 0.984 \\
\hline Lateral/medial ankle ligament injury $(n)$ & $36 / 3$ & $30 / 3$ & 0.580 \\
\hline Dominant foot: right/left $(n)$ & $35 / 4$ & $29 / 4$ & 0.546 \\
\hline Previous ankle sprain: injured ankle $(n)^{c}$ & 15 & 16 & 0.392 \\
\hline Previous ankle sprain: uninjured ankle $(n)^{\mathrm{c}}$ & 17 & 10 & 0.211 \\
\hline Type of activity at the injury $(n)$ & & & 0.125 \\
\hline Work activity & 8 & 2 & \\
\hline Everyday activity & 17 & 13 & \\
\hline Sport/recreational activity & 14 & 18 & \\
\hline Self-reported working conditions $(n)^{\mathrm{a}}$ & $4(3-5)$ & $4(2-5)$ & 0.022 \\
\hline $\begin{array}{l}\text { 6. Heavy work (lumber jack, fire fighter, } \\
\text { construction worker, etc.) }\end{array}$ & 9 & 4 & \\
\hline $\begin{array}{l}\text { 5. Moderately heavy work (truck driver, } \\
\text { scrubbing floors, etc.) }\end{array}$ & 10 & 5 & \\
\hline $\begin{array}{l}\text { 4. Moderate work (nurse, preschool teacher, } \\
\text { housework with kids, etc.) }\end{array}$ & 10 & 9 & \\
\hline $\begin{array}{l}\text { 3. Light work (hairdresser, sales person, } \\
\text { etc.) }\end{array}$ & 3 & 3 & \\
\hline $\begin{array}{l}\text { 2. Sedentary work (secretary, desk work, } \\
\text { student, etc.) }\end{array}$ & 7 & 6 & \\
\hline $\begin{array}{l}\text { 1. Do not work for reasons other than my } \\
\text { foot }\end{array}$ & 0 & 6 & \\
\hline $\begin{array}{l}\text { 0. Sick-listed or disability pension because } \\
\text { of my foot }\end{array}$ & 0 & 0 & \\
\hline
\end{tabular}

${ }^{\mathrm{a}}$ Medians and first and third quartile (Q1-Q3) are reported. ${ }^{\mathrm{b}}$ Medians and range are reported. ${ }^{\mathrm{c}}$ The same patient may have reported both injured and uninjured ankles. 
Table 2. Foot and Ankle Outcome Score (FAOS), self-reported satisfaction and physical activity ability on visual analogue scale (VAS).

\begin{tabular}{|c|c|c|c|}
\hline & $\begin{array}{l}\text { Written instruction } \\
\text { group }(n=39)\end{array}$ & $\begin{array}{l}\text { Physiotherapy } \\
\text { group }(n=33)\end{array}$ & $p$-value \\
\hline \multicolumn{4}{|l|}{ FAOS subscales ${ }^{a}$} \\
\hline Pain at 6 weeks & $72(56-83)$ & $83(69-92)$ & 0.019 \\
\hline Pain at 3 months & $86(67-100)$ & $94(83-100)$ & 0.076 \\
\hline Symptoms at 6 weeks & $61(50-86)$ & $71(59-91)$ & 0.047 \\
\hline Symptoms at 3 months & $79(64-96)$ & $89(73-96)$ & 0.169 \\
\hline Activities of daily life at 6 weeks & 87 (75-97) & $93(90-100)$ & 0.016 \\
\hline Activities of daily life at 3 months & $94(79-100)$ & $100(97-100)$ & 0.001 \\
\hline Sports and recreation function at 6 weeks & $45(35-65)$ & $75(55-90)$ & $<0.001$ \\
\hline Sports and recreation function at 3 months & $70(30-100)$ & $90(80-98)$ & 0.005 \\
\hline Quality of life at 6 weeks & $56(31-63)$ & $63(53-81)$ & 0.010 \\
\hline Quality of life at 3 months & $69(44-88)$ & $81(69-94)$ & 0.015 \\
\hline \multicolumn{4}{|l|}{ VAS questions ${ }^{b}$} \\
\hline Satisfaction at 6 weeks & $31(20-70)$ & $23(8-35)$ & 0.023 \\
\hline Satisfaction at 3 months & $24(5-53)$ & $8(3-18)$ & 0.023 \\
\hline Physical activity ability at 6 weeks & $28(20-61)$ & $15(7-29)$ & 0.006 \\
\hline Physical activity ability at 3 months & $20(5-42)$ & $4(2-15)$ & 0.004 \\
\hline
\end{tabular}




\section{Figure legend}

Figure 1. Study flowchart for the written instruction group.

Figure 2. Self-reported satisfaction and physical activity ability in the written instruction group ( $n=39)$ and the physiotherapy group ( $n=33)$. A score of $0=$ "completely satisfied/normal, no limitation” and 100 = "not satisfied at all/severely limited”. 
Patients aged 18-65 years

with an ankle sprain

assessed for eligibility

53 persons

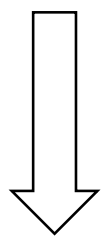

Potential participants 45 persons

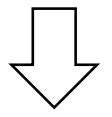

Included in the study

39 persons

\section{Excluded:}

Language $=\mathbf{2}$ persons

Earlier operation $=\mathbf{1}$ person

Other diseases/injuries $=\mathbf{4}$ persons

Physiotherapist contact at the inclusion $=\mathbf{1}$ person

\section{Dropouts:}

Did not answer the phone call $=\mathbf{1}$ person

Did not return the questionnaire $=\mathbf{5}$ persons 


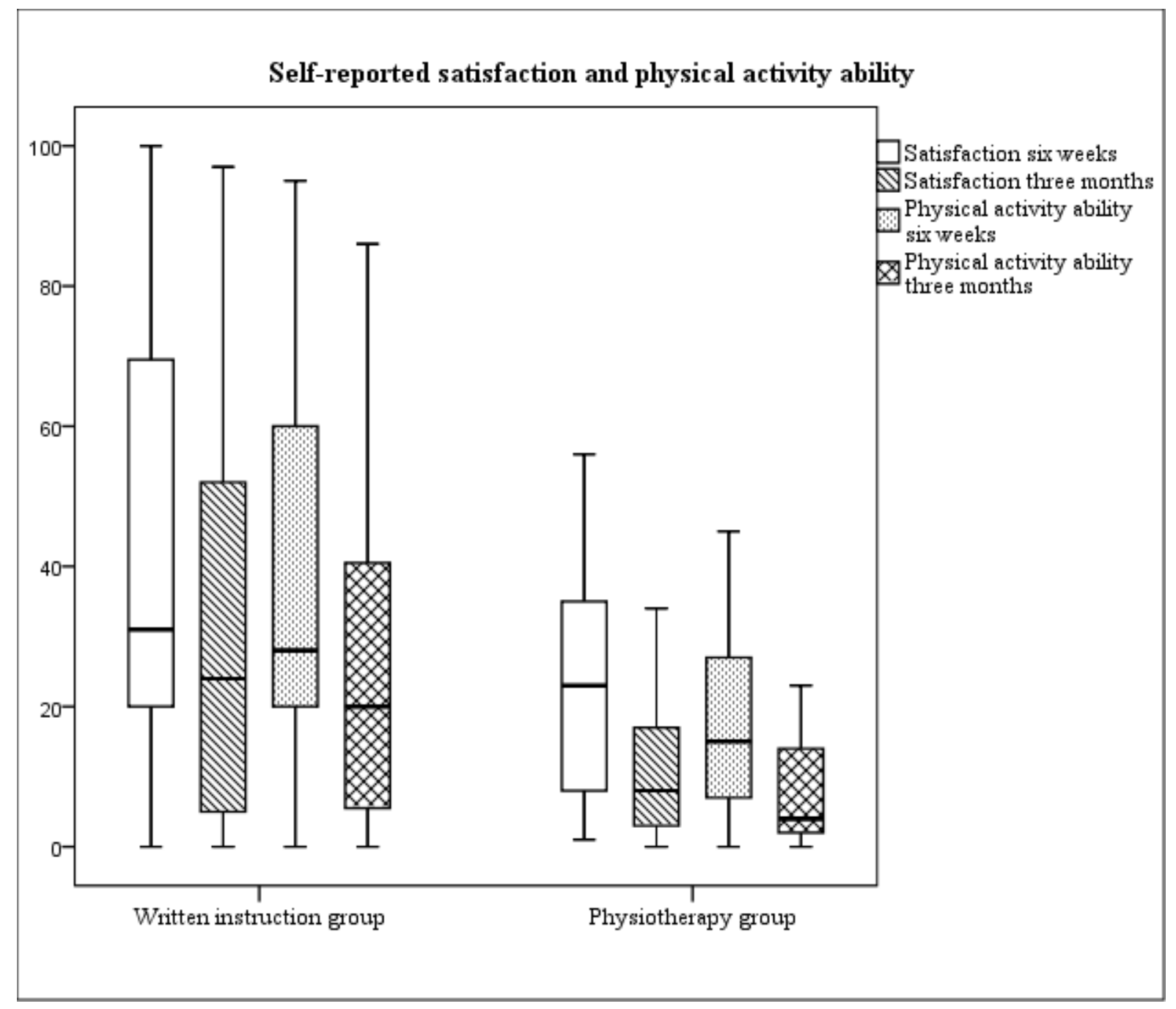




\section{Rehabilitation instructions after an ankle sprain}

\section{The foot anatomy}

The foot consists of many small bones that are joined together by ligaments and muscles. When your ankle is sprained, often one or more of these ligaments are injured. Most commonly it is the lateral ligaments on the outside of the foot that are injured (about $80 \%$ of cases). These ligaments are weaker than those on the inside of the foot. The ligaments can rupture in total or partially. Sometimes a small piece of bone is dislodged from the attachment together with the ligament, but how to take care of and treat the injury is not changed.

\section{Acute care management}

Once the injury occurs, there is bleeding in the injured area. This bleeding causes swelling, pain and difficulty in weightbearing on the foot. To reduce or stop the bleeding you can:

1. Use a tourniquet and a compression bandage

* Tourniquet - wrap an elastic bandage (pull out the elasticity of the bandage to the maximum). Start on the front foot, at the toes, and stop about $10 \mathrm{~cm}$ above the ankle. A tourniquet is important and should be used as quickly as possible after the injury. The bleeding is greatest in the first minutes. Leave the tourniquet on for 20-30 minutes, easing it for a minute and then apply a compression bandage.
* Compression bandage - (wrap with about $50 \%$ of the elasticity of the bandage) decreases the secondary swelling that arises due to the bleeding drawing fluid from the surrounding area. Use a compression bandage as long as the foot swells to counteract secondary swelling.

\section{Elevated position}

Place the injured foot as high above the heart as possible to reduce the blood flow to the injured area.

\section{Cold}

Cooling has the ability to reduce bleeding/swelling, but primarily has a pain reducing effect. Use crushed ice in a plastic bag. Remember not to put the cold directly to the skin.

\section{Walking technique}

It is important to start weight-loading on the foot as soon as possible after an ankle sprain, even if the ankle hurts. Crutches can be used during the first days to ease off the body weight, if you can't put weight on the foot due to the pain. However, it is important not to jump with your foot in the air. The injury will heal much faster if you quickly start trying to walk as normally as possible on the foot! If necessary, take painkillers to get started. 


\section{Healing}

It takes at least 6 weeks before the ligaments heal, but you should get started with mobility and rehabilitation exercises directly. These exercises are of importance to regain full function in the foot after an ankle sprain.

It is easier to regain function in your foot if the swelling decreases. Bruising on the foot can be noticed after some days. It is the natural consequence of the bleeding that occurred when tissues were injured. Some swelling may persist for several months. In order to reduce the swelling and thereby optimize the healing process it is important to get started as quickly as possible with mobility exercises. You can start with exercise 1-4 below as soon as possible after the injury, often the same day as the injury occurred.

\section{Mobility exercises}

1. Move your ankle vigorously up and down. 20 repetitions each hour or as often as possible

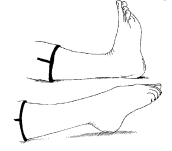

2. Nip and sprawl with your toes. 20 repetitions each hour or as often as possible

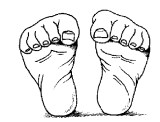

3. Draw letters of the alphabet in the air. Start with small movements and increase gradually

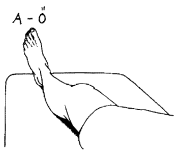

4. Use a towel or a ball to slide with your foot forwards and backwards.

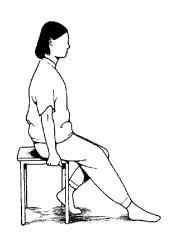

\section{Rehabilitation exercises}

After a couple of days, you can increase the training with strength-, balance- and coordination exercises. In the ligaments, there are sensory cells that detect the position and movement in the foot. When the ligaments are damaged there is an impairment of this function, which means an increased risk to reinjuring the foot. The strength in the muscles are also often lost, which decreases the stability of the foot. By performing the following strength-, balance- and coordination exercises you are going to improve your muscle strength and the ability of the sensory cells in the ligaments to detect the position and movement in the foot. To achieve a good result it is necessary that you gradually increase the severity of the exercises.

5. Toe raises on both feet at the same time. Increase the load by doing them on one foot. Compare if the feeling is the same between the feet and if you can manage as many on both feet.

6. Stand on one leg. Increase the degree of difficulty by turn your head from side to side, bouncing/throwing a ball, closing your eyes or, if possible, use a balance board.

7. If you have an elastic band or access to a pulling device (available at most gyms) this is a perfect way for exercising your foot. Attach the elastic band around the foot and pull it towards yourself. You can also attach the elastic band to pull the foot sideways, in- and outwards.
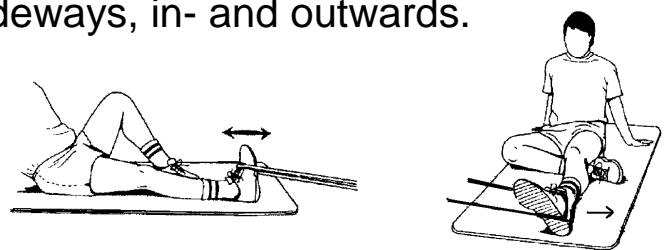
8. Stretch your calf muscles with the assistance of a wall. Do it both with your back leg straight and bent.
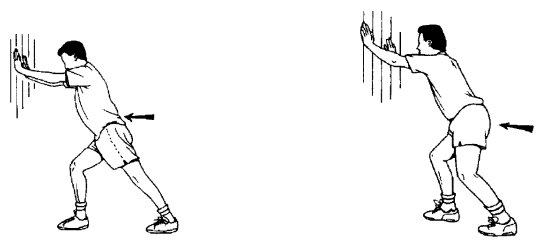

\section{Training-competition-game?}

You can conduct alternative training from the first day after the injury, to train the rest of your body. You can use an exercise bike or run with a wet vest in water, to maintain your fitness level. If your goal is to return to "tougher" activities, for example soccer, it is important that you do some jumping and running exercises in different directions (exercise 9-12). Before you return to sports it is important that you trust your foot in everyday activities. Some pain is acceptable after activity, but should be gone the next day. It is possible that tape or some kind of ankle support can complement the rehabilitation training. A physiotherapist can teach you how to tape your ankle.
11. Skate jumps from side to side. Start with small jumps and increase gradually as the foot gets better.

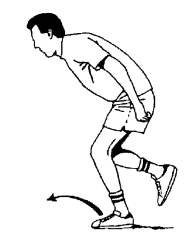

12. Start from the middle. Jump with two feet together in all directions. Increase by jumping only on the injured foot.

9. Take-offs. Start with small jumps and increase gradually as the foot gets better.

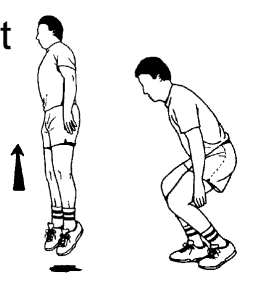

10. Jog in an eight. Switch direction, increase the speed.

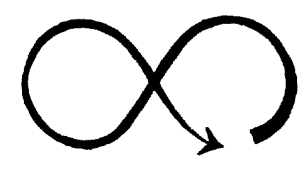

